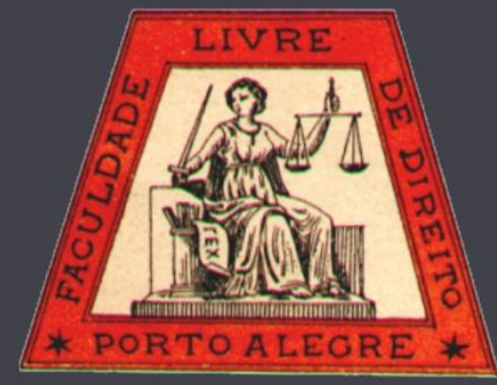

\title{
Crítica aos recursos repetitivos de acordo com a teoria dos precedentes e a função jurisdicional
}

Criticism to the repetitive appeals according to the doctrine of precedent and to the judicial function

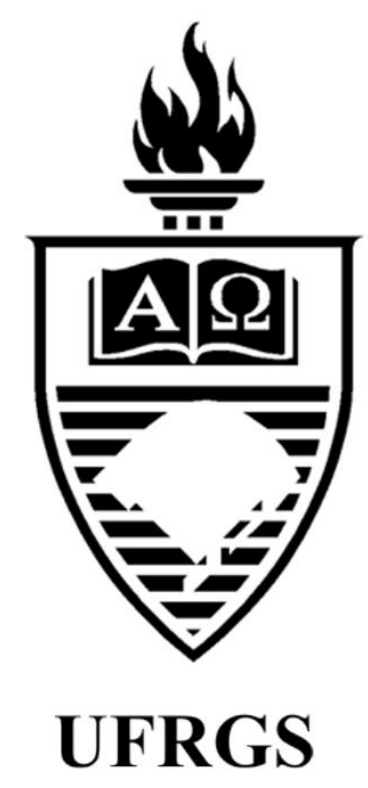

Thiago Carlos de Souza Brito

Faculdade de Desenvolvimento do Rio Grande do Sul

Revista da Faculdade de Direito da UFRGS

ISSN: 0104-6594 Site http://seer.ufrgs.br/revfacdir

Faculdade de Direito da UFRGS - Rua Riachuelo, 1317 - Centro - Porto Alegre - RS - Brasil

CEP - 90010-271 - Telefone: +55 5133083118 - Site http://www.ufrgs.br/direito/ 


\title{
Crítica aos recursos repetitivos de acordo com a teoria dos precedentes e a função jurisdicional
}

\author{
Review of same subject appeal according to the doctrine of precedent and judicial functions
}

Thiago Carlos de Souza Brito*

\begin{abstract}
REFERÊNCIA
BRITO, Thiago Carlos de Souza. Crítica aos recursos repetitivos de acordo com a teoria dos precedentes e a função jurisdicional. Revista da Faculdade de Direito da UFRGS, Porto Alegre, n. 35, p. 252-267, dez. 2016.
\end{abstract}

\begin{abstract}
RESUMO
O trabalho analisa o uso do precedente na realidade processual civil brasileira. A necessidade de uniformização jurisprudencial nada mais reflete que uma necessidade da justiça formal (igualdade de tratamento). Após a adoção dos recursos repetitivos, a possibilidade de concretização e individualização do Direito tornou-se problema recorrente. O trabalho busca apresentar o sistema processual e a estrutura do recurso repetitivo e formula críticas à legislação, partindo da teoria de Mizabel Derzi sobre a função jurisdicional. A primeira crítica refere-se à impossibilidade da concreção da decisão judicial, uma vez que o STJ e STF estabelecerão enunciados gerais e abstratos, de ampla aplicabilidade para situações consideradas médias. Em segundo lugar, altera a sistemática dos precedentes vigente no ordenamento jurídico brasileiro, ao definir a força do precedente objetivamente, em detrimento de qualquer análise de seu conteúdo.
\end{abstract}

\section{PALAVRAS-CHAVE}

Precedente judicial. Recursos repetitivos. Função jurisdicional.

\section{ABSTRACT}

This paper analyses the use of precedent in the Brazilian civil procedure reality. The need for case law standardization reflects nothing more than a need for formal justice (equal treatment). After the adoption of repetitive appeals, the possibility of implementation and individualization of Law has become a recurring problem. The study aims to present the procedural system and the structure of repetitive appeal, and formulates criticisms to the legislation from Mizabel Derzi's theory of the judicial function. The first criticism refers to the inability of concretion of the judicial decision, as the Superior Court of Justice and the Supreme Federal Court will establish broad and abstract statements of wide applicability for situations regarded as average. Second, it changes the systematics of precedents existing in the Brazilian legal system, by establishing the force of the precedent objectively, to the detriment of any analysis of its content.

\section{KEYWORDS}

Judicial Precedent. Repetitive Appeals. Judicial Function.

\section{SUMÁRIO}

Introdução. 1. A função jurisdicional e a individualização do direito na obra de Misabel Derzi. 2. Teoria dos precedentes: a aplicação do stare decisis nos sistemas de Common Law e no de Civil Law. 2.1 O stare decisis: ratio decidendi, overruling e distinguish. 3. O Recurso Especial e Extraordinário e a sistemática dos repetitivos. 4. Função dos Tribunais e os recursos repetitivos. 4.1 Função impropriamente tipificante dos Tribunais. 4.2 Inadequação da técnica de solução dos recursos repetitivos à teoria dos precedentes: o problema da desobediência ao precedente. Conclusão. Referências.

\section{INTRODUÇÃO}

A demora na prestação jurisdicional, em todas as instâncias, transformou-se em um dos temas mais discutidos na literatura especializada.
Os Tribunais superiores, especificamente o Superior Tribunal de Justiça e o Supremo Tribunal Federal, encontram-se assoberbados com um infindável número de recursos para julgar - e que somente aumenta no decorrer dos anos -,

\footnotetext{
* Professor da Faculdade de Desenvolvimento do Rio Grande do Sul - FADERGS. Doutorando em Direito Processual Civil pela Universidade Federal de Minas Gerais - UFMG. Mestre em Direito Processual Civil pela Universidade Federal de Minas Gerais - UFMG, 2013. Graduado em Direito pela Universidade Federal de Minas Gerais - UFMG, 2009. Advogado.
} 
resultado, dentre outros fatores, da cultura recursal brasileira (ALVIM, 2008, p. 169). A inoperância causada pelo excesso de recursos, por conseguinte, inviabiliza a concretização de diversos direitos. Tal problema ganha maior relevância quando se verifica que, após a promulgação da Constituição Federal de 1988, o Poder Judiciário tornou-se instrumento de compensação dos déficits de funcionalidade dos outros Poderes (THEODORO JUNIOR et al., 2010, p. 16).

Com efeito, após o início da década de 90 do século passado, inúmeros mecanismos foram inseridos no Código de Processo Civil de 1973, com vistas a retirar os entraves e, em determinado grau, acelerar a entrega da prestação jurisdicional nas instâncias superiores. A preocupação com a melhora da técnica procedimental objetivou a diminuição da litigiosidade e a inviabilização das causas de violações de direito que são dirimidas por meio do processo. ${ }^{1}$ Assim, foram incluídas no sistema jurídico a possibilidade de antecipação da tutela jurisdicional, a criação da fase de cumprimento de sentença (processo sincrético), as alterações no regime do recurso de agravo contra decisão interlocutória, a súmula vinculante e a repercussão geral no âmbito do Supremo Tribunal Federal, dentre outras.

Nessa esteira, um novo Código de Processo Civil foi discutido e aprovado nas Casas do Poder Legislativo. Nota-se, dentre as reformas no processo, a inserção de institutos originários do sistema de common law, com especial relevo na

\footnotetext{
${ }^{1}$ Nesse sentido, afirma Dierle Nunes (2011, p. 45): “A análise dos processualistas arraigada aos textos legislativos e a compreensão das técnicas vem se mostrando ineficiente do ponto de vista de legitimidade e de operatividade do sistema jurídico, eis que tal postura somente permite a busca por soluções técnicas para as consequências (alta litigiosidade, utilização de litigiosidade de interesse público, utilização de jurisdição como espaço contramajoritário, entre outras), mas não viabiliza o trato das causas que induzem a profusão de demandas e a utilização do processo."

2 Afirmam Alexandre Melo Franco Bahia e Aline Hadad Ladeira (2014, p. 277): “É de se ver que as várias reformas
}

valorização das decisões proferidas pelos tribunais superiores. ${ }^{2}$

Destaca-se, no presente trabalho, a sistemática dos recursos especial e extraordinário repetitivos. Mecanismo procedimental importado da experiência jurídica alemã (em terras teutônicas conhecido como Musterverfahren), foi inserido pela Lei $\mathrm{n}^{\circ} 11.672 / 08$, que modificou o CPC de 1973, com o objetivo de reduzir a quantidade de recursos julgados e racionalizar o trabalho dos magistrados (RIBEIRO, 2009, p. 617).

A sua escolha e a sua manutenção no ordenamento jurídico brasileiro, entretanto, merecem uma detida análise. Isso porque o Estado moderno erigiu a segurança jurídica como princípio fundamental, que exige, para sua efetividade, coerência e previsibilidade do direito posto (MARINONI, 2010, p. 492).

Nesse diapasão, as decisões judiciais assumem importante função no ordenamento jurídico, sendo verdadeira fonte do direito, uma vez que servem para concretização, no sentido kelseniano (BUSTAMANTE, 2012, p. 101), da norma jurídica. Para atingir tais objetivos, ela deve ser resultado de detida análise dos elementos fáticos da controvérsia, com a efetiva possibilidade de participação dos interessados, decorrência natural do direito de ação.

Todavia, a sistemática do recurso especial e extraordinário repetitivo, tal qual prevista no Novo Código de Processo Civil, não coaduna com a concretização do direito pelo Poder Judiciário.

legislativas ocorridas em nosso ordenamento jurídico nas últimas décadas permitiram a entrada de institutos incomuns à tradição do civil law, inspirando, sobretudo, na valorização do precedente oriundo do common law. Basta ver, por exemplo, a edição da EC 45/2004 que institui entre nós a denominada súmula vinculante (art. 103-A da CF/1988), além das reformas legislativas do Código de Processo Civil que instituíram as denominadas súmulas obstativas de recurso ou, ainda, deram poderes ao relator para prover (ou não) monocraticamente recurso quando haja súmula ou jurisprudência dominante." 
Pretende-se demonstrar que a escolha pela importação do sistema alemão de julgamento por recursos repetitivos apresenta duas vicissitudes, que podem ser assim sintetizadas: impossibilita a concreção da decisão judicial, uma vez que a corte - in casu, o Superior Tribunal de Justiça e Supremo Tribunal Federal -, estabelecerá enunciados gerais e abstratos, de ampla aplicabilidade para situações consideradas médias, sem a concretude esperada pelo jurisdicionado e (ii) altera a sistemática dos precedentes vigente no ordenamento jurídico brasileiro, estabelecendo a força do precedente objetivamente, em detrimento de qualquer análise de seu conteúdo.

Não se pretende, por óbvio, esgotar as críticas possíveis à sistemática de julgamento dos recursos repetitivos, mas apenas trazer algumas contribuições, em nosso entender, pertinentes ao debate.

\section{A FUNÇÃO JURISDICIONAL E A INDIVIDUALIZAÇÃO DO DIREITO NA OBRA DE MISABEL DERZI}

Necessário se faz, para sustentar os argumentos do presente trabalho, uma análise da função do Poder Judiciário na sociedade. Isso porque, em decorrência da relevância que os precedentes assumem na argumentação jurídica, como fonte legítima do Direito, a própria atividade judicial deve ser repensada.

A atividade jurisdicional, em hipótese alguma, pode ser reduzida à mera declaração do direito, uma vez que o julgador, ao resolver a controvérsia, cria a norma jurídica para o caso concreto e individualiza o direito. Em consequência disso, a teoria da função

\footnotetext{
${ }^{3}$ Nesse sentido, Thomas da Rosa de Bustamante (2009, p. 69): "Sem embargo, seria ingênuo e ilegítimo concluir que essa forma de pensar estaria inexoravelmente vedada no sistema jurídico brasileiro, na medida em que ela se fundamenta na praticidade, que constitui 'um autêntico princípio jurídico', já que apresenta os traços da
}

jurisdicional deve ser suficiente para se adequar à realidade.

Como defende Aulis Aarnio (apud BUSTAMANTE, 2013, p. 66), a análise da prática forense depende de uma teoria que permita uma relação intrínseca e constitutiva entre ambas.

Neste ínterim, merece menção o posicionamento de Misabel Derzi. Partindo do estudo sobre as normas pertinentes ao Direito Tributário, sustenta prevalecer no Direito brasileiro a execução simplificadora da lei, amplamente utilizada pela Administração Pública na aplicação da legislação fiscal. O referido modo de pensar é chamado, erroneamente (DERZI, 2007, p. 67), de tipificante, uma vez que cria tipos (conceitos rígidos e fechados).

A origem do pensamento tipificante tem fundamento no tatbestände do direito alemão, assim definido por Misabel Derzi (2007, p. 70):

\footnotetext{
Tipificar tem o sentido amplo de abstrair as particularidades individuais, para colher o que é comum ou repetitivo. Tipo será, então, o que resultar desse processo de abstração generalizante, vale dizer, a forma média ou frequente, ou aquela especificamente representativa, ou ainda, o padrão normativo ideal.
}

Não sem razão, o pensamento tipificante tem assento garantido no ordenamento jurídico pátrio, uma vez que permite uma simplificação e padronização da aplicação da norma jurídica, para atender ao princípio da praticidade e permitir que tenha ela maior porosidade (BUSTAMANTE, 2013, p. 70). Como é evidente, o princípio da praticidade tem por demais importância para o Direito, pois facilita a execução da lei. ${ }^{3}$ Em uma sociedade cada vez mais massificada, na qual situações idênticas devem ser igualitariamente regulamentadas, o referido princípio - sem

generalidade e abstração, 'irradiando os seus efeitos sobre múltiplas normas', e 'contempla valor considerado fundamental para a sociedade, qual seja, a viabilização da adequada execução do ordenamento jurídico, no campo tributário'." 
dúvidas um princípio jurídico - tem o condão de permitir a concretização do princípio da igualdade formal.

Inquestionável que o destinatário de tal aplicação tipificada do direito é certamente o legislador, autorizado pela Constituição da República Federativa do Brasil a editar normas que sejam abstratas o suficiente para atingir um sem número de situações similares (BUSTAMANTE, 2013, p. 70). Para tanto, ele utilizará presunções, ficções e padronizações legais.

No entanto, considerando a sua própria característica, tal raciocínio deve ser evitado pelos agentes públicos que necessitam de maior grau individualização do direito, uma vez que o pensamento tipificante, em sua própria essência, desconsidera toda e qualquer particularidade do caso concreto. Isso porque o pensamento tipificante pretende, com a maior clareza possível, uma padronização decisória.

Todavia, tal prática foi erroneamente transportada para o Poder Judiciário, que resulta em grave problema para o jurisdicionado, pois importa na execução simplificadora da lei (BUSTAMANTE, 2013, p. 70).

Nenhuma novidade há na afirmativa de que o papel institucional do Poder Judiciário é decidir, de forma clara e concisa, o caso concreto, entregando aos litigantes a solução destinada somente àquele caso, vez que é resultante da análise de todas as suas peculiaridades. Por conseguinte, considerando a natureza de sua função, o Poder Judiciário não pode, em suas decisões, utilizar de instrumentos que gerem uma padronização decisória. A decisão, para ser considerada jurisdicional, deve respeitar os elementos oriundos do caso concreto.

Sendo assim, qualquer técnica ou instrumento que importe na simplificação da decisão jurisdicional implica na alteração de sua função precípua, desvirtuando o objetivo da jurisdição de pacificar os litígios.

\section{TEORIA DOS PRECEDENTES: A APLICAÇÃO DO STARE DECISIS NOS SISTEMAS DE COMMON LAW E NO DE CIVIL LAW}

Ademais, antes de prosseguir no raciocínio, alguns elementos da teoria dos precedentes devem ser rememorados.

A necessidade de respeitar as decisões pretéritas, proferidas pelos tribunais, possui longa tradição no Direito brasileiro. Ainda que inserido na tradição do civil law, com as notáveis influências da Revolução Francesa e sua confiança na lei enquanto principal fonte do direito, é possível notar o traço de vinculação às decisões judiciais característico do common law. Desde a lusitana figura dos "assentos", inserida nas Ordenações Filipinas e mantida durante o Brasil Imperial, "a jurisprudência nunca perdeu por completo o valor de guia para os julgamentos" (MOREIRA, 2007, p. 300).

Todavia, a despeito de sua contínua importância, a teoria jurídica dos precedentes foi pouco - ou quase nada - desenvolvida na literatura especializada do Brasil durante os séculos XIX e XX. Aponta Thomas da Rosa de Bustamante (2012, p. 252), ao acompanhar o posicionamento de Luís Roberto Barroso, que "vigorava na tradição romano-germânica um modelo de Estado Legislativo assentado sobre o monopólio estatal da produção jurídica e sobre o princípio da legalidade [...]." Por conseguinte, na tradição brasileira do civil law, poucas eram as ferramentas metodológicas para a interpretação e aplicação dos precedentes (BUSTAMANTE, 2012, p. 252).

Sendo assim, diante da já apontada inserção de instrumentos processuais do common law em nossa sistemática no final do século $\mathrm{XX}$, foi necessário volver para a experiência dos países filiados ao referido sistema de Direito, de modo a 
aproveitar, naquilo é fosse possível, o seu cabedal teórico.

Com efeito, naquela tradição jurídica, preocupados com as garantias de segurança e de previsibilidade do ordenamento jurídico, a literatura especializada tentou racionalizar o uso dos precedentes, por meio da doutrina do stare decisis (BAHIA; LADEIRA, 2014, p. 280). Em tempo, importante destacar que no common law inexiste sinonímia entre "doutrina dos precedentes" e stare decisis. A eficácia vinculante dos precedentes tem recente assento no common law, que existiu por séculos sem o stare decisis (BAHIA; LADEIRA, 2014, p. 280).

Esclareça-se, no entanto, o conceito de stare decisis. Até mesmo porque nem toda decisão judicial pode ser considerada um precedente vinculante, ou seja, uma decisão com o denominado binding effect. Para que ela atinja tal condição, deve ser dotada de determinadas características específicas que a distinguem das demais manifestações judiciais.

Aponta Jin Evans (1987, p. 35) que a doutrina do precedente se consolidou na Inglaterra no século XIX. No final do século XVIII, era reconhecida a prática de seguir o precedente, identificado como importante $\mathrm{o}$ suficiente para servir de referência para as decisões posteriores. Mas a doutrina do stare decisis ainda não estava vigente, uma vez que não haviam sido identificadas as suas regras de aplicação e as situações nas quais o precedente era estritamente vinculativo ou poderia ser afastado (EVANS, 1987, p. 45).

Neste diapasão, interessante notar que, durante a primeira metade do século XIX, por influência do Positivismo Jurídico que floresceu na Inglaterra à época, que reconhecia um restrito poder criador do juiz (BUSTAMANTE, 2012, p. 253), o precedente no common law encontrava o seu elemento vinculante na autoridade da corte que proferiu a decisão, independente da sua fundamentação (BUSTAMANTE, 2012, p. 284).
De acordo com essa visão, defendida inicialmente por Blackstone, o common law era composto apenas pelos costumes do reino declarados pela corte (EVANS, 1987, p. 36). Além disso, a teoria então vigente sustentava que em cada decisão era possível identificar apenas uma ratio decidendi (BUSTAMANTE, 2012, p. 253). Apesar dos problemas decorrentes de tal posicionamento, identificado enquanto "teoria declaratória" dos precedentes, é notável a consolidação da teoria do stare decisis no final do século XIX, no sentido de que cada corte estava vinculada aos precedentes das cortes superiores e as cortes superiores estavam vinculadas aos seus próprios precedentes (EVANS, 1987, p. 64).

Em contrapartida, outra teoria surgiu como resposta à teoria declaratória. Percebeu-se que as cortes, ao decidirem o caso concreto, não só declaravam o direito, mas também o criavam. Jeremy Bentham - mordaz defensor da codificação na Inglaterra - e Austin demonstraram os problemas do common law decorrentes da incerteza de um sistema que, na verdade, poderia ser definido como "judge-made law". Tal ficção foi chamada de "infantil" por Austin, em passagem já famosa, na qual afirma ser "a ficção mais infantil empregada pelos nossos juízes, que o Judiciário ou common law não é elaborado por eles, mas algo milagroso feito por ninguém, existindo, eu suponho, eternamente, e meramente declarado pelos juízes de tempos em tempos" (EVANS, 1987, p. 67-68). Partindo de tais premissas, obviamente simplificadas no presente trabalho, a teoria constitutiva reconhece a capacidade de criação da corte diante do caso concreto.

$\mathrm{Na}$ verdade, a disputa entre as duas teorias serve como pano de fundo para o reconhecimento da autoridade da decisão e a consequente necessidade de segui-la. Contudo, tal discussão não é pressuposto para o stare decisis (MARINONI, 2010, p. 26). 
Com o passar dos anos, a teoria do stare decisis modificou-se, destacadamente em razão do ocaso do Positivismo e a ascensão da argumentação jurídica. Assim, o fundamento do caráter de vinculação do precedente deixou de ser a autoridade da corte que o proferiu e passou a ser a sua capacidade de persuasão. Como afirma Thomas da Rosa de Bustamante (2012, p. 253):

Devemos seguir precedentes não mais apenas porque eles constituem Direito positivo formalmente produzido por alguma autoridade institucionalmente autorizada a criar Direito, mas porque os precedentes passam a ser vistos como uma exigência da própria ideia de "razão prática". Não pode haver um sistema jurídico racional sem um método universalista e imparcial de aplicação do Direito positivo. ${ }^{4}$

Vale enfatizar: o precedente judicial nos países de common law detém o caráter de vinculação de acordo com a sua capacidade de produzir convencimento, e não simplesmente em decorrência da autoridade da corte que proferiu a decisão. Neste ínterim, assumiu ele a função de fonte do direito, seja em razão do princípio da universalizabilidade (fundamento moral), no sentido Kantiano, seja em decorrência da própria configuração de estrutura hierarquizada que possui o Poder Judiciário (fundamento institucional), que inclusive dispõe de mecanismos de uniformização de jurisprudência. ${ }^{5}$

Não obstante, é necessário verificar a sua capacidade de vinculação (binding effect) ao mesmo tribunal que proferiu a decisão e aos demais tribunais de instâncias inferiores. Sugere

\footnotetext{
${ }^{4}$ Interessante notar que a mudança decorrente da aplicação da teoria da argumentação jurídica fundamenta, de forma moral, a possibilidade de superação do precedente, através do sistema do overruling, como conclui Bustamante: "O modelo de Estado Constitucional contemporâneo exige que todo ato de aplicação judicial do Direito atenda, na máxima medida possível, à pretensão de justificabilidade racional que nos proíbe de considerar a 'autoridade' dos juízes e tribunais como uma razão excludente para as decisões posteriores. Isso significa que uma doutrina do precedente absolutamente vinculante não é mais compatível com a exigência de justificabilidade mantida pelas Constituições
}

Thomas da Rosa de Bustamante (2012, p. 301) que:

Podemos observar, portanto, que após esses pequenos ajustes a classificação de Peczenik passa a corresponder à classificação estabelecida por Aarnio para as fontes do Direito em geral: Os precedentes vinculantes em sentido forte (1) são considerados fontes do Direito em grau máximo (must-sorces); os vinculantes em sentido frágil (2), fonte prima facie obrigatórias (should-sources); e os not formally binding and not having a force but providing further support, que prefiro denominar simplesmente de precedentes persuasivos (3), valem apenas como fontes do Direito permitidas (may-sources).

Em razão das limitações impostas pela própria proposta do presente trabalho, impossível aprofundar o estudo dos critérios de definição do peso do precedente em determinado ordenamento jurídico. Porém, as bases teóricas necessárias para sustentar as conclusões a que chegamos foram no final apresentadas.

\subsection{O stare decisis: ratio decidendi, overruling e distinguish}

Não obstante a gradação da vinculação do precedente, a teoria do stare decisis não importa na automática repetição das mesmas decisões para os novos casos ajuizados perante o Poder Judiciário. Tampouco é estendido o efeito vinculante à decisão judicial em sua integralidade.

$\mathrm{Na}$ verdade, a aplicação do stare decisis depende da identificação da razão de decidir (ratio decidendi) extraída do caso concreto (GOLDSTEIN, 1987, p. 5-6), que incidirá sobre o

democráticas, pois será sempre teoricamente possível que em um caso futuro as razões aduzidas para o overruling de uma regra jurisprudencial superem as que militam em favor da manutenção desta mesma regra."

5 A título de exemplo, basta mencionar o incidente de uniformização da jurisprudência previsto no art. 476, do antigo CPC. Todavia, o referido incidente não teve continuidade no Novo CPC. Entretanto, vale mencionar a hipótese de interposição de recurso especial com fundamento na alínea "c", inc. III, do art. 105 da CF, com evidente finalidade de uniformização da jurisprudência. 
novo litígio levado até o Poder Judiciário, desde que superadas as técnicas de não-aplicação.

Com efeito, necessário esclarecer que o significado do precedente é encontrado na sua fundamentação, onde pode ser encontrada a razão de decidir que deve constar de forma expressa na decisão judicial.

A ratio decidendi, entendida enquanto a "norma universalizável que pode ser extraída de um precedente judicial"6, em sua identificação, não pode ser dissociada dos fatos do caso originário. $\mathrm{Na}$ tradição do common law há está superada a máxima de que as razões do julgado o obiter dictum -, não fazem parte julgado. MacCormick (apud BUSTAMANTE, 2012, p. 256), afirma que "é na enunciação das opinions para o fim de justificação de decisões que os juízes estabelecem precedentes e constroem o case law."

Não obstante, importante diferenciar a ratio decidendi do obiter dictum, distinção que remonta à própria evolução do common law (MARINONI, 2010 , p. 232). Isso porque, uma vez que se reconhece a vinculação da nova decisão à do caso anterior, é necessário definir qual parte da fundamentação do julgado é relevante, separando-a daquilo que não é essencial. Segundo Neil Duxbury (in MARINONI, 2010, p. 234), pode ser o obiter dictum entendido enquanto "passagens que [...] se apresentam de diversas formas, como as que não são necessárias ao resultado, as que não são conectadas com os fatos do caso ou as que são dirigidas a um ponto que nenhuma das partes buscou arguir".

Para o jurista brasileiro, acostumado com a análise da decisão judicial de acordo com os elementos previstos do Código de Processo Civil - relatório, fundamentação e dispositivo - a compreensão da ratio decidendi é tarefa tormentosa, uma vez que ela emerge de todos os

\footnotetext{
${ }^{6}$ BUSTAMANTE, 2012, p. 257. Importante destacar que, como aponta Luiz Guilherme Marinoni (2010, p. 223), "não há sinal de acordo, no common law, acerca de uma definição
}

elementos em conjunto, sem se confundir com qualquer deles (MARINONI, 2010, p. 222).

A ratio decidendi, de toda forma, deve ser entendida partindo-se de uma teoria integrativa das teorias declaratória e positivista (BUSTAMANTE, 2012, p. 264). Ademais, em uma só decisão, é possível a existência de mais de uma ratio decidendi (BUSTAMANTE, 2012, p. 271). Ao perquirir a norma encontrada na fundamentação que o juiz apresenta para a sua decisão, pode o julgador do novo caso concreto encontrar regras que podem servir como paradigmas para resolver casos futuros.

Considerando que a teoria dos precedentes é propositiva e visa a solucionar casos idênticos que se apresentam no futuro, uma vez identificada a ratio decidendi, descartando-se o obiter dictum, terá o juiz que fazer o necessário distinguishing, ou seja, a obrigatória distinção entre o caso em julgamento e a ratio decidendi já existente, com vistas a verificar se existe similitude entre os fatos discutidos em ambos os casos, apto a justificar a aplicação do procedente (MARINONI, 2010, p. 222).

A relevância do distinguishing na teoria dos precedentes pode ser demonstrada, inclusive, no tema dos recursos repetitivos, conforme dispõe o art. 1.037, $\S 9^{\circ}$, do CPC. Tal artigo determina expressamente que, na hipótese de suspensão de processo em razão do julgamento na sistemática dos recursos repetitivos, o julgador verifique se é possível efetuar a distinção entre o caso julgado e aquele que foi afetado pelo recurso especial ou extraordinário repetitivo.

Importante aqui esclarecer que, caso inaplicável o precedente ao novo caso em julgamento, não será ele revogado. O distinguishing é o procedimento utilizado apenas para identificar eventual precedente aplicável ao

de ratio decidendi ou mesmo do método capaz de permitir a sua identificação". 
caso concreto, de modo que sua inadequação não o torna necessariamente incorreto.

A revogação dos precedentes, de acordo com a literatura especializada do common law, é feito por meio do overruling. Com efeito, o Direito, enquanto ciência social, é resultado de forças históricas que podem conformar-se de diversas formas e necessita de constantes alterações. Por conseguinte, um canal que possibilite a mutação da norma jurídica, nela incluída a decisão judicial, deve permanecer sempre aberto. Portanto, um precedente deve ser revogado, segundo afirma Melvin Eisenberg (1991, p. 121), se não mais encontra congruência social, consistência sistêmica e suporte de valores de estabilidade.

Inquestionável a aproximação e convergência dos sistemas de common law e civil law, especialmente após o novo CPC. Perceptível que os precedentes, no processo civil brasileiro, deixaram de ser meramente persuasivos e assumiram relevância na argumentação jurídica.

\section{O RECURSO ESPECIAL E EXTRAORDINÁRIO E A SISTEMÁTICA DOS REPETITIVOS}

No contexto de valorização do precedente enquanto fonte do Direito, os tribunais superiores assumem notável preponderância em tal produção normativa.

A sistemática dos recursos especial e extraordinário é por demais conhecida, tornandose despicienda maiores digressões. Cumpre agora explicitar a sistemática dos julgamentos repetitivos.

Com efeito, o instituto dos recursos repetitivos foi introduzido no CPC de 1973 por meio da Lei $n^{\circ} 11.672$, de 8 de maio de 2008, de restrita incidência apenas no âmbito do recurso especial, e regulamentado, no STJ, pela Resolução $n^{0}$ 8, de 7 de agosto de 2008.
Sua origem, contudo, remonta ao Direito Alemão. Ainda que filiado à tradição do Direito europeu continental, os precedentes possuem relevante importância como fonte do direito naquele ordenamento jurídico. Surgiu com o objetivo de permitir maior celeridade no julgamento de uma situação específica e pontual, decorrente das demandas ajuizadas por investidores na Bolsa de Valores Alemã, fundadas no mesmo fato - a divulgação de informações falsas pela Deutsche Telekom nos anos de 1999 e 2000 (RIBEIRO, 2009, p. 624) -, bem como com o objetivo de elaborar uma decisão uniforme, proferida pelo tribunal. Interessante destacar que a lei que instituiu Musterverfahren previu, de forma expressa, um prazo de validade para o procedimento, que expiraria no ano de $1^{\circ}$ de novembro de 2010.

Perceptível que o legislador alemão optou pela sistemática dos chamados test claims, na qual as questões comuns de ações idênticas - ou com elevado grau de proximidade de pleito - são decididas através de um processo paradigma escolhido previamente.

Partindo de tal premissa, o legislador brasileiro estabeleceu que, segundo dispõe os arts. 1036 e seguintes do Novo CPC, diante de uma multiplicidade de recursos fundados em idêntica questão de direito, é cabível a admissão de um ou mais recursos representativos da controvérsia. Estes, por sua vez, serão encaminhados ao órgão julgador competente do STJ, com a devida suspensão/sobrestamento da tramitação dos outros recursos que abordem a mesma questão central (WAMBIER; VASCONCELOS, 2008, p. 30).

Importante aqui destacar que pouca alteração houve na sistemática de julgamento do recurso repetitivo no NCPC. Como afirma Jorge Amaury Maia Nunes (2014), preocupou-se o legislador em detalhar o procedimento de seleção e sobrestamento dos processos submetidos à sistemática, aproveitando-se a experiência dos 
tribunais desde a modificação processual ocorrida em 2008.

Após o julgamento pelo STF ou STJ do recurso representativo, duas possibilidades se apresentam. Na hipótese de a decisão impugnada pelo recurso sobrestado estar em conformidade com o acórdão do tribunal superior, o recurso especial terá o seu seguimento denegado. Por outro lado, caso o mencionado acórdão divirja do julgado proveniente do Tribunal Superior, os tribunais a quo poderão adequar-se, proferindo novo julgamento. Caso não o faça, o recurso será remetido para a Corte Superior, a qual poderá reformar a decisão em desconformidade com o entendimento vencedor.

O objetivo de tal procedimento já podia ser encontrado já no Projeto de Lei n ${ }^{\circ} 1.213$, de 2007, embrião do instituto em questão: a necessidade de se imprimir maior celeridade aos ritos processuais, tendo em vista que o Judiciário se encontrava, e ainda se encontra, abarrotado de processos. À época, destacou-se que o desiderato de celeridade não deveria ferir o direito ao contraditório e à ampla defesa. ${ }^{7}$

No entanto, conforme se passa a demonstrar, a sistemática dos recursos especiais repetitivos, da forma como é aplicada pelo STF e STJ, é inconstitucional, uma vez que restringe a participação do cidadão no processo, deslegitimando-o, bem como desconsidera as situações fáticas que deram origem ao precedente.

\section{FUNÇÃO DOS TRIBUNAIS E O RECURSO REPETITIVO}

Após toda a apresentação dos elementos necessários para aprofundar a discussão, cumpre aqui analisar a constitucionalidade da inclusão e

\footnotetext{
${ }^{7}$ Vale mencionar o seguinte trecho do Projeto de Lei $\mathrm{n}^{\circ}$ 1.213 de 2007: "Sob a perspectiva das diretrizes estabelecidas para a reforma da Justiça, faz-se necessária a alteração do sistema processual brasileiro com o escopo de
}

da manutenção do instituto dos recursos repetitivos no ordenamento jurídico pátrio.

\subsection{Função impropriamente tipificante dos Tribunais}

$\mathrm{Na}$ esteira do posicionamento de Misabel Derzi, parece claro que a função do Poder Judiciário está estritamente ligada à capacidade de, partindo do caso concreto, elaborar a norma para aquele litígio específico.

Contudo, a inclusão da sistemática dos recursos repetitivos impede tal atuação. Isso porque implicam na redução da complexidade dos casos, restringindo os argumentos apresentados por ambas as partes, de modo a também reduzir a complexidade interpretativa do próprio julgador. Ademais, o STF e o STJ distanciam-se ainda mais do jurisdicionado, preocupados em decidir teses jurídicas ao invés do caso concreto.

Pode-se ponderar, de forma correta, que o modo de construção das decisões jurisdicionais nos recursos repetitivos não é tão abstrativa quanto às súmulas editadas tanto pelo próprio STF e STJ.

Contudo, as decisões decorrentes de julgamento sob a sistemática dos recursos repetitivos são dotadas de determinado grau de abstração que as dissociam do caso concreto, exatamente com o objetivo de atingir um sem número de situações presumidamente, mas não comprovadamente, idênticas. Um pensamento tipificante, portanto. Porém, o Poder Judiciário não está constitucionalmente autorizado a valerse de instrumentos que gerem uma padronização decisória. A decisão, para ser considerada jurisdicional, por sua própria natureza, deve respeitar os elementos oriundos do caso concreto.

conferir racionalidade e celeridade ao serviço de prestação jurisdicional, sem, contudo, ferir o direito ao contraditório e à ampla defesa." 
A necessidade de implementação de tal instituto no ordenamento jurídico brasileiro é eminentemente prática. Em razão da preponderância que assumiu o Poder Judiciário, como visto, na promoção dos direitos constitucionalmente garantidos, mas não efetivados pelos demais Poderes, novos tipos de litigiosidade foram apresentados ao julgador. Como apontam Humberto Theodoro Júnior, Dierle Nunes e Alexandre Bahia (2010, p. 24), além da já conhecida pretensão individual, o Judiciário deve agora responder por demanda coletiva (que envolvem direitos difusos, coletivos e individuais homogêneos), bem como por demanda de massa, "que dá margem a propositura de ações repetitivas ou seriais, que possuem como base pretensões isomórficas, com especificidades, mas que apresentam questões (jurídicas e/ou fáticas) comuns para a resolução da causa." Partindo de tais premissas, perceptível que os recursos repetitivos foram inseridos no ordenamento para a solucionar a sobrecarga de trabalho decorrente das demandas de massa, uma vez que não haviam instrumentos procedimentais para responde-las. Por oportuno, vale mencionar o posicionamento de Humberto Theodoro Júnior, Dierle Nunes e Alexandre Bahia (2010, p. 24-25):

Desde algum tempo as reformas têm se concentrado na tentativa de uniformização da jurisprudência a todo custo. O suposto é que seja possível estabelecer "standards interpretativos" a partir do julgamento de alguns casos: um tribunal de "maior hierarquia", diante da multiplicidade de casos, os julgaria abstraindo-se de suas especificidades e tomandolhes apenas o "tema" a "tese" subjacente. Definida a tese, todos os demais casos serão julgados com base no que foi pré-determinado; para isso, as especificidades destes novos casos também serão desconsideradas para que se concentre apenas na "tese" que lhe torna idênticos aos anteriores.

No entanto, a solução para a litigiosidade coletiva e de massa não passa pela padronização decisória, resultante em um julgamento uniformizado, no qual determinado tribunal (in casu, o STF e o STJ) decide tese jurídica e desconsidera os pormenores do caso concreto.

A necessidade de solucionar o problema da eficiência processual (THEODORO JUNIOR et al., 2010, p. 21) compeliu o legislador, sem respaldo constitucional, a autorizar ao magistrado proferir decisões judiciais simplificadas e genéricas, supostamente hábeis a resolver um sem número de casos.

Ao optar pela simplificação das demandas por meio de decisões padronizadas para casos supostamente idênticos, parece ser evidente que o legislador erigiu a eficiência quantitativa enquanto sua única preocupação, desconsiderando a necessidade de adequar o sistema processual à elaboração de uma decisão específica para cada conflito levado ao Poder Judiciário.

Em tempo, cabe ressaltar que a existência de um julgamento pela sistemática dos recursos repetitivos parte do pressuposto de que existem casos idênticos (art. 1.036 do NCPC). Todavia, o julgamento de casos em bloco necessitaria de uma norma jurídica perfeita, disponível desde logo para aplicação, sem espaço para singularidade. A complexidade da vida, porém, é muito maior do que pode prever qualquer legislador ou julgador, de modo que a simples utilização de decisão pronta para o caso não significa a decisão - na impossibilidade de se utilizar o adjetivo "justa" qualificada para o litígio.

Ao que tudo indica, o Poder Judiciário está sobrecarregado com infindáveis litígios para decidir, oriundos de causas semelhantes dos denominados "litigantes habituais". Por conseguinte, a opção pela padronização decisória é mero remédio para combater as consequências de outros males, cuja solução é independente do Poder Judiciário. Como sintetizam Humberto Theodoro Júnior, Dierle Nunes e Alexandre Bahia (2010, p. 30), “não é possível mais pensar somente nas consequências (demandas em profusão) eis que do ponto de vista institucional o 
sistema jurídico funcionaria bem melhor se impedíssemos as causas delas (não cumprimento de direitos fundamentais sociais etc.)".

Sendo assim, a simplificação da decisão jurisdicional do recurso especial e extraordinário repetitivo implica na alteração de função precípua do Poder Judiciário.

\subsection{Inadequação da técnica de solução dos recursos repetitivos à teoria dos precedentes: o problema da desobediência ao precedente}

Ademais, é possível formular outra crítica à sistemática dos recursos repetitivos. Ao que tudo indica, a necessidade de utilização de uma técnica de julgamento calcada na identificação resolução dos recursos repetitivos aponta um problema na obrigatoriedade dos precedentes do STF e do STJ.

Com efeito, somente a hipótese de os tribunais de justiça e tribunais regionais federais rejeitarem, de forma reiterada, a aplicação do precedente já firmado pelo STF e STJ, justificaria a existência da sistemática dos recursos repetitivos.

Isso porque, caso a teoria do stare decisis, tal qual como construída no common law, fosse seguida pelos tribunais brasileiros, bastaria que o primeiro litígio sobre determinada matéria chegasse até o STF e STJ para que, agindo dentro de sua competência constitucionalmente delimitada, definisse o referido tribunal qual a interpretação legítima. Após o seu posicionamento, os tribunais a ele subordinados, diante de um caso similar, deveriam aplicar o precedente do tribunal superior (BUSTAMANTE, 2012, p. 325).

Entretanto, encontra-se na prática forense uma realidade completamente distante. Lastreados em uma interpretação assistemática da Constituição Federal e do princípio do livre convencimento, os juízes de primeiro grau e desembargadores em grau recursal insistem em posicionar-se de forma diametralmente oposta ao entendimento do STF ou STJ. Como afirma Luis Guilherme Marinoni (2010, p. 495):

\begin{abstract}
Ou melhor: a técnica do julgamento por amostragem e do sobrestamento dos recursos repetitivos constitui um paliativo ao grave problema da insubordinação à autoridade dos precedentes do Superior Tribunal de Justiça - espoliado, pela prática forense, de sua missão constitucional de uniformizar a interpretação da lei federal.
\end{abstract}

Sendo assim, o que pretende a técnica dos recursos repetitivos nada mais é do que a obrigatoriedade da observância de um precedente. Objetiva-se, portanto, um tipo de precedente no sentido forte, de modo que as cortes inferiores sejam obrigadas a segui-lo de forma quase absoluta, similar ao sistema procedimental inglês.

Todavia, a construção de um sistema de precedentes brasileiro não pode se originar somente na via legislativa, pois uma cultura jurídica não pode ser modificada por meio de uma simples alteração da lei. Para mudá-la, necessário se faz um esforço para melhorar a formação dos juristas, em especial, dos julgadores, com a devida atenção ao estudo dos precedentes e da sua importância no ordenamento jurídico enquanto fonte de direito.

Acrescente-se que tal movimento de valorização dos precedentes deve partir das próprias cortes especiais. Ora, de nada adianta pregar a vinculação vertical se a corte que proferiu o julgado não se mantém vinculada às suas próprias decisões. Hoje, é possível perceber a constante mudança de posicionamento do STJ em diversas matérias, reflexo da preocupação dos julgadores em expor as suas opiniões pessoais, abalando qualquer tentativa de construção de um stare decisis. Se o próprio tribunal não respeita suas decisões, como exigir dos demais igual respeito? Sobre o tema, interessante síntese é apresentada por José Rodrigo Rodrigues (2013, p. 14): 
Quando pensam sobre um caso concreto, os juristas estão mais preocupados em apresentar suas opiniões pessoais sobre o problema que têm diante de si do que em demonstrar analítica e racionalmente a correção da solução que defendem. Debater tal solução perante seus colegas também fica em segundo plano. Cada juiz parece se relacionar com a esfera pública de forma independente: sua individualidade está acima das eventuais "razões do Tribunal" que, aliás, não organiza os fundamentos dos votos em uma decisão coerente e tampouco impõe o dever de se elaborar um voto oficial da corte.

Ademais, a sistemática de julgamento por recursos repetitivos desconsidera os fundamentos da decisão enquanto elemento basilar para a identificação da força do precedente. Há, na verdade, uma objetivação do precedente, reconhecendo a sua vinculação de acordo com o fato de que, simplesmente, foi ele decidido pelo STF e STJ em conformidade às regras do CPC e a Resolução $n^{0} 8$ do STJ, capazes por si sós de conferir-lhe tal força. Vale dizer, o valor do precedente independe do seu conteúdo. ${ }^{8}$

Assim, em nada contribui a inserção e a manutenção do julgamento pela sistemática dos recursos repetitivos à teoria dos precedentes, vez que não enfrenta $o$ real problema da desobediência das decisões das cortes superiores pelas cortes e juízes que lhes são subordinados.

Em tempo, cumpre ressaltar que o legislador parece confundir, no que toca ao processo, "causas individuais repetitivas" com "direitos individuais homogêneos" (MARINONI, 2010, p. 496). Ainda que relativamente ao direito material estejam as duas questões próximas, enquanto a primeira refere-se a processos individuais de demandas individuais, a segunda versa sobre direitos individuais demandados coletivamente. Assim, nas ações coletivas, além da diferença quanto à legitimidade ad causam, a coisa julgada possui efeito erga omnes, inexistente no recurso repetitivo.
Acrescente-se que, durante a tramitação da ação coletiva, todos os interessados poderão participar e, na hipótese de decisão desfavorável ao titular do direito individual, poderá ele mover a sua ação. Contrario sensu, no caso do sobrestamento de uma ação individual, o titular do direito terá restrita participação no julgamento do recurso paradigma, bem como, no caso de decisão desfavorável, não terá solução alternativa (NUNES, 2012).

Assim, parece claro que o problema enfrentado pelo Poder Judiciário brasileiro de sobrecarga de demandas de massa, ou seja, aquela originada da propositura de ações repetitivas ou seriais, não será resolvido pela técnica procedimental escolhida pelo legislador.

\section{CONCLUSÃO}

Não resta dúvida de que a centenária lição de Ruy Barbosa, no sentido de que justiça tardia é, na verdade, denegação da justiça, continua válida.

Os problemas enfrentados pelo Poder Judiciário, assoberbado por um quase sem número de processos pendentes de julgamento, devem ser solucionados o quanto antes, sob pena de atingir a confiança do jurisdicionado.

Todavia, a solução de tais problemas não pode passar por um instituto que, da forma como vem sendo utilizado pelo Poder Judiciário brasileiro, viola a natureza da função jurisdicional, cria standards interpretativos, simplesmente desconsiderando a especificidade do caso concreto.

Diante disso, ao nosso sentir, deveria ser o instituto dos recursos repetitivos utilizado a uma aplicação restrita e delimitada para situações previamente estabelecidas pela Corte Superior, tal qual ocorreu na experiência do Direito Alemão.

${ }^{8}$ MARINONI, 2010, p. 492-493. 
Até mesmo porque, ao contrário daquilo que se esperava, a sistemática dos recursos especiais repetitivos não atingiu aquela que seria a sua principal destinação, a saber, a redução dos recursos julgados pelo STF e STJ. De acordo com as informações disponibilizadas pelo próprio Superior Tribunal de Justiça, o número de processos pendentes de julgamento não retrocedeu.

Sendo assim, pensar o processo constitucional democrático impõe ao pesquisador do direito a postura teórica e prática que deve se afastar da análise de institutos e técnicas processuais e voltar-se para o estudo do panorama de todo o sistema. Desse modo, de nada adiantam reformas legislativas que desconsideram a cultura jurídica nacional e as vicissitudes de nosso sistema.

O problema permanece, uma vez que o remédio pensado não se destina à doença identificada.

\section{REFERÊNCIAS}

ALVIM, J. E. Carreira. Recursos Especiais Repetitivos: Mais uma Tentativa de Desobstruir os Tribunais. Revista de Processo, Revista dos Tribunais, São Paulo, v. 162, p. 169-189, 2008.

BAHIA, Alexandre Melo Franco; LADEIRA, Aline Hadad. 2014. O Precedente Judicial em Paralelo a Súmula Vinculante: pela (re)introdução da faticidade no mundo jurídico. Revista de Processo, Revista dos Tribunais, São Paulo, v. 234, p. 277-302, 2014.

BUStAmANTE, Thomas da Rosa de. Teoria do Precedente Judicial. Rio de Janeiro: Noesis, 2012.

. Súmulas, Praticidade e Justiça: um olhar crítico sobre o direito sumular e a individualização do direito à luz do pensamento de Misabel de Abreu Machado Derzi. In: COELHO, Sacha Calmon Navarro. Segurança Jurídica: Irretroatividade das Decisões Judiciais Prejudiciais aos Contribuintes. Rio de Janeiro: Forense, 2013, p. 65-106.

DERZI, Misabel de Abreu Machado. Direito Tributário, Direito Penal e Tipo. 2. ed. São Paulo: Revista dos Tribunais, 2007.

EISENBERG, Melvin Aron. The Nature of the Common Law. Cambridge, Mass.: Harvard University Press, 1991.

EVANS, Jim. Change in the Doctrine of Precedent during the Nineteenth Century. In: GOLDSTEIN, Laurence. Precedent in Law. Oxford: Oxford University Press, 1987.

GOLDSTEIN, Laurence. Precedent in Law. Oxford: Oxford University Press, 1987.

MARINONI, Luiz Guilherme. Precedentes Obrigatórios. São Paulo: Revista dos Tribunais, 2010.

MOREIRA, José Carlos Barbosa. Súmula, Jurisprudência, Precedente: uma escalada e seus riscos. In: . Temas de Direito Processual. 9. série. São Paulo: Saraiva, 2007. 
NUNES, Dierle José Coelho. Padronizar decisões pode empobrecer o discurso jurídico. Revista Consultor Jurídico, São Paulo, 06 ago. 2012. Disponível em: $<$ http://www.conjur.com.br/2012-ago06/dierle-nunes-padronizar-decisoes-empobrecer-discurso-juridico $>$. Acesso em: 20 jun. 2014.

. Processualismo Constitucional Democrático e o Dimensionamento de Técnicas para a Litigiosidade Repetitiva: a litigância de interesse público e as tendências não compreendidas de padronização decisória. Revista de Processo, Revista dos Tribunais, São Paulo, v. 199, p. 45-64, 2011.

NUNES, Jorge Amaury Maia. Resolução de demandas e recursos repetitivos no novo CPC. Migalhas, [s.1.], 03 dez. 2014. Disponível em: <http://www.migalhas.com.br/dePeso/16,MI212189,11049resolucao + de + demandas $+\mathrm{e}+$ recursos + repetitivos + no + novo + CPC $>$. Acesso em: 26 dez. 2014.

RIBEIRO, Cristiana Hamdar. A Lei dos Recursos Repetitivos e os Princípios do Direito Processual Civil Brasileiro. Revista Eletrônica de Direito Processual, ano 4, v. 5, 2009.

RODRIGUES, José Rodrigo. Como Decidem as Cortes: para uma crítica do direito (brasileiro). Rio de Janeiro: Editora FGV, 2013.

THEODORO JUNIOR, Humberto; NUNES, Dierle; BAHIA, Alexandre. Breves Considerações sobre a Politização do Judiciário e Sobre o Panorama de Aplicação no Direito Brasileiro: análise da convergência entre o civil law e o common law e dos problemas da padronização decisória. Revista de Processo, Revista dos Tribunais, São Paulo, v. 189, 2011.

WAMBIER, Luiz Rodrigues; VASCONCELOS, Rita de Cássia Corrêa de. Recursos Especiais Repetitivos: reflexos das novas regras (Lei 11.672/2008 e Resolução 8 do STJ) nos processos coletivos. Revista de Processo, Revista dos Tribunais, São Paulo, v. 163, 2008.

Recebido em: 18/11/2016

Aceito em: 26/12/2016 
